\title{
A developmental study of the speed of comprehension of printed sentences
}

\author{
DONALD G. DOEHRING and IRENE M. HOSHKO \\ McGill University, Montreal, Quebec, Canada HSG $1 A 8$
}

\begin{abstract}
Simple printed sentences with a highly predictable word missing were presented to normal readers from Grades 1 through 11 . The children had to say the missing word as rapidly as possible. Error rates were low enough that response latency could be assessed from Grade 2 on. There was a steady decrease in latency from the lower to the higher grades, and latency was highly correlated with the speed of oral reading of letters, words, nonsense syllables, and sentences. The results are discussed with regard to mechanisms underlying sentence comprehension.
\end{abstract}

Reading comprehension can take a number of different forms, ranging from the identification of isolated words to the appreciation of subtle inferences. It is generally viewed as a very complex process which cannot easily be explained (Gibson \& Levin, 1975) or measured (Anderson, 1972). The present report is concerned with the acquisition of one particular form of reading comprehension, the rapid comprehension of sentences.

In a previous paper (Doehring, 1976), it was reported that skills for rapid responses to letters, syllables, and words begin to develop as early as first grade and that children make use of the semantic-syntactic constraints provided by sentence structure and meaning to speed their oral reading as early as the first year of reading. A more direct estimate of the speed of sentence comprehension was provided by a cloze-type task (Bickley, Ellington, \& Bickley, 1970) which was administered at the same time as the tests on which the previous report was based. The results for the cloze task are given separately here, since they were inappropriate for the previous within-task analysis.

Printed sentences with one word deleted were presented one at a time, and the child was required to say the missing word as rapidly as possible. The sentences were simple and the deleted words were intended to be so highly predictable that even the youngest child who could understand the remainder of the sentence would be able to guess the missing word. To the extent that this goal was achieved, response latency should reflect the speed of sentence comprehension, plus whatever time might be needed for word retrieval and articulation

This research was supported by Grants 604-7-858 from the Canadian Department of National Health and Welfare and MA-1652 from the Medical Research Council of Canada. The writers wish to thank the Protestant School Board of Greater Montreal and the staffs of Herbert Symonds, Willingdon, and Iona Elementary Schools and Montreal West High School for their cooperation, and Bonnie Bryans, Agnes Ling, and Daniel Ling for comments on the manuscript. Request reprints from D. G. Doehring, 1266 Pine Avenue West, Montreal, Quebec, Canada H3G 1A8. time. It is of interest to determine how the speed with which children can comprehend sentences changes during reading acquisition and to relate speed of comprehension to other reading-related skills. Such information should aid in the specification of the components of reading comprehension.

\section{METHOD}

\section{Subjects}

Teachers in several Montreal schools were asked to select children who had no problems in any area of academic achievement, were neither too low nor too high in reading achievement, were in the normal grade for their age (i.e., age 6 years when beginning first grade), and had English as their first language. The sentence comprehension test was given as part of a large study, most of the results of which have been reported elsewhere (Doehring, 1976). The 150 children tested included 5 girls and 5 boys each in the first and second halves of kindergarten, Grade 1, and Grade 2, and during the first halves of Grades 3 through 11. The cloze task was too difficult for the kindergarten children and the children in the first half of Grade 1 . Partial results are reported for the 20 children in the second half of Grade 1 and the first half of Grade 2, who had some success with the task, and more complete results are given for the remaining 100 children. None of the children had hearing problems or uncorrected visual problems. Reading was taught with a variety of materials by a variety of methods in the schools which these children attended. There was no special emphasis on any one method in any one of the schools.

\section{Procedure}

Each sentence was typed on a single line on an $18 \times 20 \mathrm{~cm}$ card in IBM Courier 72 type, with the deleted word indicated by an underlined blank space. The 16 sentences and the responses accepted as correct are listed in Table 1 . They were chosen on the basis of a preliminary study with normal adults. Of the 16 omitted words, 8 were function words and 8 were nouns.

The cards were placed on a stand in front of the child and uncovered one at a time in the order shown in Table 1 . The child was told to read the sentence silently and supply the missing word as rapidly as possible. Two practice trials were given. As the experimenter uncovered each sentence she said "Now." The test was given following a series of oral reading tests (Doehring, 1976) and required 5-10 min for completion.

All responses were tape recorded, and the time between the experimenter's prompt and the child's response was later measured to the nearest $.01 \mathrm{sec}$ by observation of the time that 
Table 1

Test Sentences in Order of Presentation, With Correct Responses in Parentheses

(Once) upon a time, a princess lived in a magic land. Wash your face (and) hands before supper.

These apples are too green (to) eat.

I worked hard (all, to, every, that, one, each) day.

The (dog, cat, boy, man) chased the cat up the tree.

Mother asked me to buy a (loaf, bag) of bread at the store.

The story had a happy (ending, end).

John's pen ran out of (ink, food).

A wind (from, in, of, to) the north froze the pond.

I dropped my fork (on, onto, upon) the floor.

No, dinner's not ready (yet, now, dear).

They lived happily ever (after).

I put (salt, gravy) and pepper on my meat.

Blow out the (candles) on your birthday cake.

Our hen laid an (egg).

Look both ways before you cross the (street, road).

elapsed on a stop clock between the experimenter's "Now" and the child's response. This procedure gave an error of measurement of less than .1 sec.

\section{RESULTS}

Median incorrect responses made on the 16 sentences by the 10 children in each grade are shown in Table 2 . The error rate was high in Grades 1.5 and 2, but decreased abruptly from Grade 2.5 on and remained below $10 \%$ thereafter. The ninth sentence, where the correct response was supposedly "from," proved to be a bad choice, since there were at least four errors in each grade. On the remaining sentences there tended to be two or fewer errors per grade after Grade 2 .

Table 2 also shows the median of the median latencies for the 10 children in each grade, where errors were scored as infinitely long latencies. The error rate was too high in Grade 1.5 to permit a latency estimate, and latency could be estimated for only seven of the Grade 2 children. After the very long median latency in Grade 2, the median time required for supplying deleted words dropped sharply to about $4 \mathrm{sec}$ in Grades 2.5 and 3, remained between 2 and $3 \mathrm{sec}$ from Grades 4 through 7 , and then decreased below $2 \mathrm{sec}$ and began to approach $1 \mathrm{sec}$ from Grade 8 to 11 . Since all children in Grade 2.5 and above made fewer than 8 errors, median latency

Table 2

Median Errors and Latencies on the 16 Sentences for the $\mathbf{1 0}$ Children in Each Grade

\begin{tabular}{lccccc}
\hline Grade & Errors & Latency* & Grade & Errors & Latency* \\
\hline 1.5 & 8.0 & & 6 & 1.5 & 2.1 \\
2 & 6.0 & 12.2 & 7 & 1.0 & 2.4 \\
2.5 & 2.5 & 3.9 & 8 & 1.0 & 1.8 \\
3 & 1.5 & 4.1 & 9 & .5 & 1.5 \\
4 & 1.0 & 2.8 & 10 & 0 & 1.3 \\
5 & 1.0 & 2.4 & 11 & 1.0 & 1.3 \\
\hline
\end{tabular}

*In seconds could be used for statistical analysis of latency changes for all children in these grades. With individual medians converted to logs to obtain homogeneity of variance between grades, there was a significant difference among grades $(F=17.95)$. Further analysis by the Newman-Keuls test showed a significant decrease ( $p<.01$ ) between Grades 3 and 4, 5 and 9, and 7 and 10 .

Log latency of sentence comprehension was next correlated with log latency of response on four of the other tests which had been given to the children (Doehring, 1976). These tests, which were most directly comparable to the sentence comprehension task, included speed of oral reading of strings of lowercase letters, nonsense syllables, unrelated common words, and words in simple sentences. Even after the covariance attributable to chronological age had been removed by partial correlation, the correlations for the total group of 100 children were quite high, being .51 for letters, .65 for nonsense syllables, .75 for words, and .82 for sentences. The differences among these correlations were all significant beyond the .05 level (Ferguson, 1971). Thus, latency of response on the cloze task was most highly correlated with the oral reading task on which responses were speeded by the comprehension of sentence structure and meaning, demonstrating that response latency on the cloze task provided a suitable indicator of the time required for comprehension. The higher correlations for word than for nonsense syllable reading and for nonsense syllable than for letter reading suggest that response latency on the cloze task also reflected the speed of comprehending the meaning of individual words and the speed of transforming printed syllables to spoken form. The high residual correlation with letter reading is probably the result of other perception, association, and response factors common to the cloze task and the oral reading task.

\section{DISCUSSION}

Simple sentences were not rapidly comprehended in the lower grades, probably because many of the requisite skills had not yet been overlearned to the point of automaticity (LaBerge $\&$ Samuels, 1974). By the middle grades, the average reader was able to comprehend the sentences within $2 \frac{1}{2} \mathrm{sec}$, and the time required for comprehension was reduced to less than $1 \frac{1 / 2}{\mathrm{sec}}$ in the upper grades. These times probably underestimate the rate of silent comprehension of written sentences, since they include whatever additional time was required for the retrieval and articulation of the deleted word. However, it seems evident that the average reader continues to develop rapid comprehension skills even for simple sentences well beyond the primary school years.

The correlational results provide a further indication that reading comprehension in children may involve the joint operation of several different skills, as suggested by Golinkoff (1975, 1976), LaBerge and Samuels (1974), Perfetti and Hogaboam (1975), and other writers. That performance of the cloze task was related to the speed of reading syllables and words suggests that these skills are involved in sentence reading, but that cloze task performance was even more highly correlated with sentence reading suggests that some additional skill is involved in sentence comprehension. This skill probably involves processing of the 
logical-semantic-grammatical relationships among words. Since sentence, word, and syllable skills are each undoubtedly composed of a variety of subskills, reading comprehension in children appears to be far from a unitary process even where the simplest of sentences is concerned.

Further research is needed to delineate the acquisition of skills for rapid sentence comprehension. The complexity of the process demands multiple observations of systematically varied parameters, including stages of acquisition, for the formulation of suitably detailed explanations. It is particularly important to determine the extent to which processing at the semanticsyntactic level in the mature reader may become independent of word and syllable reading (cf. Bradshaw, 1975; Smith, 1975).

\section{REFERENCES}

ANderson, R. C. How to construct achievement tests to assess comprehension. Review of Educational Research, $1972,42,145-170$.

Bickiey, A. C., Ellington, B. J., \& Bickiey, R. T. The cloze procedure: A conspectus. Journal of Reading Behavior, 1970, 2, 232-239.
Bradshaw, J. L. Three interrelated problems in reading: A review. Memory \& Cognition, 1975, 3, 123-134.

Doenring, D. G. Acquisition of rapid reading responses. Monographs of the Society for Research in Child Development, 1976, 41, Serial number 165.

Ferguson, G. A. Statistical analysis in psychology and education (3rd ed.). New York: McGraw-Hill, 1971.

GiBson, E. J., \& Levin, H. The psychology of reading. Cambridge, Mass: MIT Press, 1975.

Golinkoff, R. M. A comparison of reading processes in good and poor comprehenders. Reading Research Quarterly, 1975-1976, 11, 623-659.

LABERge, D., \& SAmuels, S. J. Toward a theory of automatic information processing. Cognitive Psychology, 1974, 6, 293-323.

Perfetti, C. A., \& Hogaboam, T. The relationship between single word decoding and reading comprehension skills. Journal of Educational Psychology, 1975, 67, 461-469.

SMITH, F. Comprehension and learning. New York: Holt, Rinehart, \& Winston, 1975.

(Received for publication December 3, 1976.) 